\title{
軸流圧縮機動翼列の失速点近傍における非定常流れ挙動
}

\section{Unsteady Flow Behavior in an Axial Compressor Rotor at Near-Stall Conditions}

\author{
○柴本 康広（九大院） \\ 盆子原 翔（三菱重工業） \\ 郡司嶋 智（九大）
}

\author{
中村 典生（九大院） \\ 正 岩切 健一郎（九大院） \\ 正古川 雅人（九大）
}

\begin{abstract}
Yasuhiro SHIBAMOTO, Kyushu University, Motooka744, Nishi-ku, Fukuoka City, Fukuoka Noritaka NAKAMURA, Kyushu University, Motooka744, Nishi-ku, Fukuoka City, Fukuoka Sho BONKOHARA, Mitsubishi Heavy Industries, Ltd. Ken-ichiro IWAKIRI, Kyushu University, Motooka744, Nishi-ku, Fukuoka City, Fukuoka Satoshi GUNJISHIMA, Kyushu University, Motooka744, Nishi-ku, Fukuoka City, Fukuoka Masato FURUKAWA, Kyushu University, Motooka744, Nishi-ku, Fukuoka City, Fukuoka
\end{abstract}

Effects of the rotor tip clearance on the performance and the stall phenomena at near-stall conditions in an axial flow compressor rotor have been investigated experimentally. For two different tip clearances, the internal flow structure and the unsteady flow behavior was analyzed by measuring the wall pressure on the casing and the three-dimensional velocity field downstream of the rotor. It is found that the stall inception originates from the separation of blade suction surface boundary layer for the small tip clearance and from the breakdown of tip leakage vortex for the large tip clearance.

Key Words: Turbomachinery, Axial Compressor, Near-stall Condition, Separation Vortex, Vortex Breakdown

\section{1. 緒言}

軸流圧縮機動翼列における全体性能と内部流れ構造との 間には密接な関係があり, 動翼列内部の流動現象の解明はそ の高性能化や性能推定という観点から非常に重要である。し かし軸流圧縮機内では，翼端すき間における漏れ流れ，翼面 境界層の外向き流れによる低エネルギー流体の集積, 二次流 れに伴う局所的なはく離など, 非常に複雑な非定常三次元粘 性流れとなっている.さらに，これらの効果が圧縮機性能に 及ぼす影響力は，圧縮機の機械的条件によって大きく異なる そのため, 数值計算による研究が進む現在においても, 高精 度の内部流動現象の予測には実験的解析手法による研究が なお必要である。

これまでの研究により，本供試圧縮機において翼端すき間 の大きさによって失速点近傍での性能・失速特性が異なるこ とが報告されている．翼端すき間の小さな場合，失速点近傍 で高い圧維機性能を示し，失速点において突如スパイク型の 小スケール擾乱が発生し, 連続的に成長して旋回失速状態に いたる ${ }^{(1)}$ 。一方，翼端すき間の大きな場合は，明確な失速点 を示さず，小スケール擾乱が発生・消滅を繰り返す旋回不安 定擾乱が生じた後, ゆるやかに旋回失速へと移行する ${ }^{(2)}$.

そこで本研究では，異なる翼端すき間を持つ本供試圧縮機 に対して，ケーシング壁面圧力分布の非定常测定および動翼 下流の内部流動測定をおこない, 失速点近傍における非定常 流れ挙動について調查した.

\section{2. 実験装置}

本供試軸流圧縮機の概略図を図 1 に示寸.ケーシング直径は

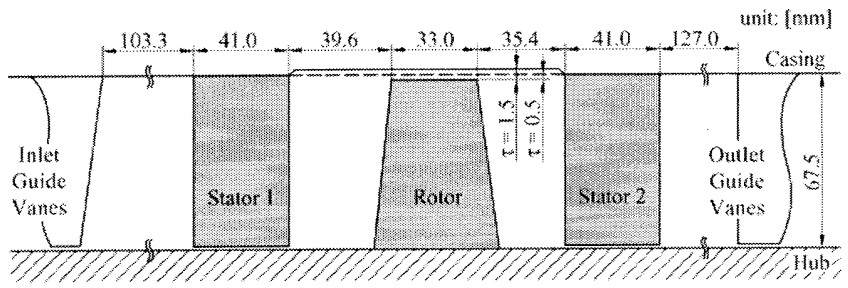

Fig. 1 A schematic view of test section
$450 \mathrm{~mm}$ で, 試験部は入口案内羽根, 静翼 1 , 動翼, 静翼 2 , 出口 案内羽根で構成され ${ }^{(3)}$, 設計回転数は $1800 \mathrm{rpm}$ である. 動静翼 を組み合わせた段落は, 設計流量係数 $(\phi) 0.5$, 設計圧力上昇 係数 $(\phi) 0.43$, 八ブ比 0.7 の軸流圧縮機中間段を対象としたもの である. 動翼入口における設計渦形式は平均半径で反動度 $50 \%$ の一定旋回角形式である. 動翼枚数 24 枚, 静翼枚数 22 枚, 翼弦長 $50.1 \mathrm{~mm}$ であり，翼端すき間は $\tau=1 \%$ 翼端コード $(0.5 \mathrm{~mm})$ と $\tau=3 \%$ 翼端コード $(1.5 \mathrm{~mm})$ に変更可能である. なお, 実験における測定回転数は $1300 \mathrm{rpm}$ とした。

\section{3. 実験方法}

図 2 に本試験装置における圧力-流量特性曲線を示す.横軸 は流量係数 $\phi$, 縦軸は圧力上昇係数 $\phi$ である. 本研究では, こ の $\phi=0.40,0.38,0.36,0.34$ の計 4 点において熱線流速計による 内部流動測定および高応答圧力センサ (Kulite XCS-062)による 壁面静圧測定を行った。兩測定において, 動翼に同期したデー タをサンプリングするために, 周期的多点抽出法 ${ }^{(4)}$ を用いてデー 夕計測を行った。

内部流動測定には，定温度型(定抵抗型) 熱線流速計を使用

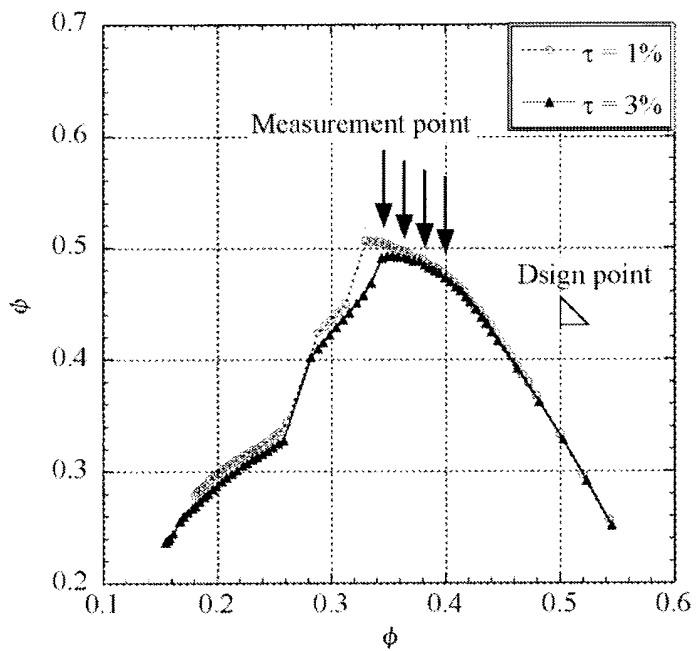

Fig. 2 Pressure-rise characteristics of compressor stage 
した. 使用した熱線は傾斜角 $45^{\circ}$ の単一傾斜型である. 測定位 置を図 3 の破線で示している. 測定点数は半径方向に $\mathrm{r} 1$ 加 $\mathrm{r} 18$ までの 18 点, 周方向は 600 点に分割し, 1 ピッチ間あたり 25 点 の測定を行った.さらに各測定位置でプローブ軸を回転させて 17 方向 $\left(13.5^{\circ}\right.$ おきに 1 回転)のデータを 512 回転分サンプリン グした.

壁面静圧測定では, ケーシング壁面に動翼前縁 $9.1 \mathrm{~mm}$ 上流 の位置から動翼後縁 $2.9 \mathrm{~mm}$ 下流の位置まで $5.0 \mathrm{~mm}$ 間隔で計 10 力所にわたつて圧力センサを埋設し, 壁面静圧を測定した. 図 3 上部はその軸方向位置を示している.

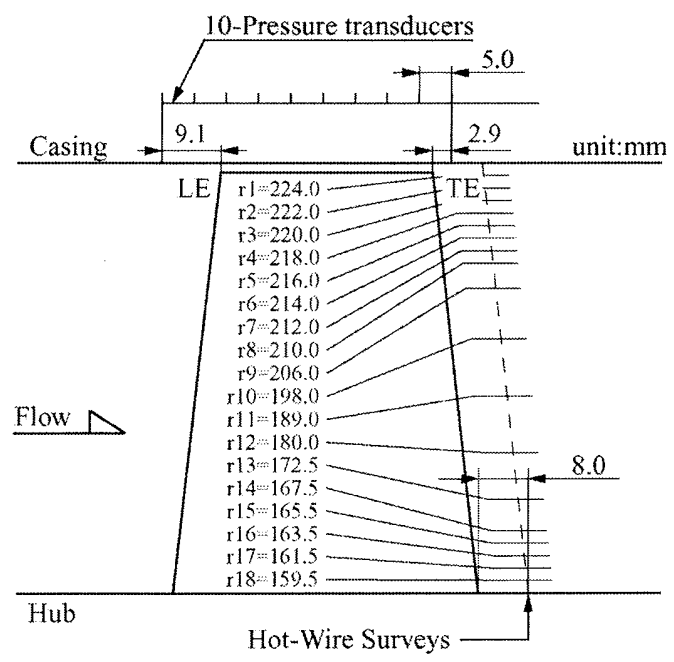

Fig. 3 Measurement locations
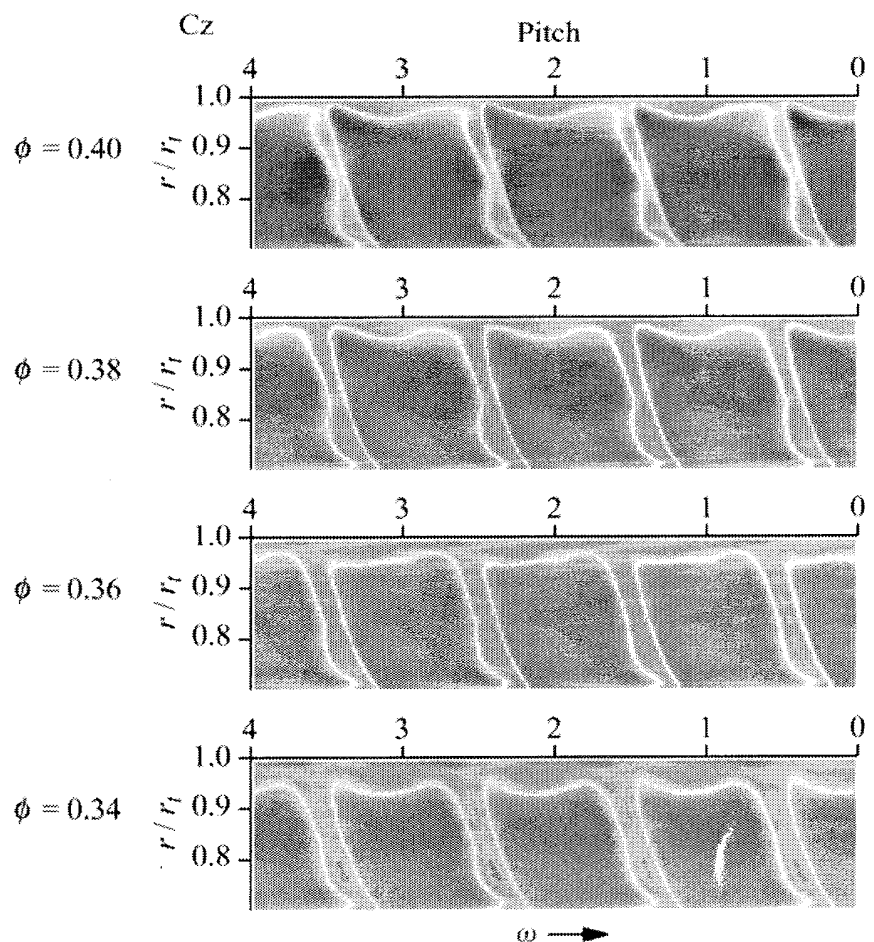

(a) $\tau=3 \%$

\section{4. 実験結果および考察}

4-1 内部流動測定 動翼後縁 $8.0 \mathrm{~mm}$ 下流における内部流動 測定結果を図 4 に示す。図中(a)，(b)は翼端すき間がそれぞ れ $\tau=3 \%, 1 \%$ の場合の测定結果であり，上から流量係数 $\phi$ $=0.40,0.38,0.36,0.34$ の順で表示している. 図は測定位置 での軸方向速度分布 $\mathrm{Cz}$ (動翼先端周速に相当した動圧で無 次元化）を示しており, 縦軸は半径位置（動翼先端半径で無 次元化)，横軸は Pitch 番号を示している. なお，図の下部に 動翼回転方向を示している.

$\tau=3 \%$ において， $\phi=0.40$ の $\mathrm{Cz}$ 速度分布図を見ると，翼間 のケーシング面近傍で速度欠損域が見られる。これは翼端漏 れ渦のブロッケージ効果によりケーシング面近傍の流れが 八ブ側へ転向したためである。また動翼負圧面ではウェーク 領域において速度欠損域が確認され，八ブ面近傍で厚くなっ ている. $\phi=0.38$ から $\phi=0.36$ にかけて，ケーシング面近傍の 速度欠損域はスパン方向に拡大し，ウェーク領域の速度欠損 域は周方向に拡大している。このことから，翼間におけるブ ロッケージ効果の増大と翼負圧面における境界層の発達が 流れ場に顕著に現れていることが分かる. $\phi=0.34$ になると， ケーシング面近傍の速度欠損域はさらに拡大している。過去 の研究 ${ }^{(1)}$ から, 本供試圧縮機では $\phi=0.34$ において翼端漏れ 渦がスパイラル型の渦崩壊を生じることが確認されている. これにより，ケーシング面近傍においてさらに強いブロッ ケージ効果が作用したと考えられる。また，動翼負圧面では ウェーク領域において速度欠損域が周方向へわずかに桩大 していることがわかる。これは流量の減少により翼の迎角が 増大し，翼負圧面での境界層の発達が増大したためであると 考えられる.また，この速度久損域のハブ面近傍では，常に 周方向に厚い領域が存在している。これはハブ面における二 次流れが動翼負圧面との角で渦を巻いているためであると 考えられる。

$\tau=1 \%$ の場合， $\phi=0.40$ においてケーシング面近傍におけ る速度久損域は $\tau=3 \%$ 場合に比ベスパン方向に小さい。こ れは $\tau=1 \%$ の方が翼端漏れ渦が弱く，そのブロッケージ効果

$\mathrm{C} z$
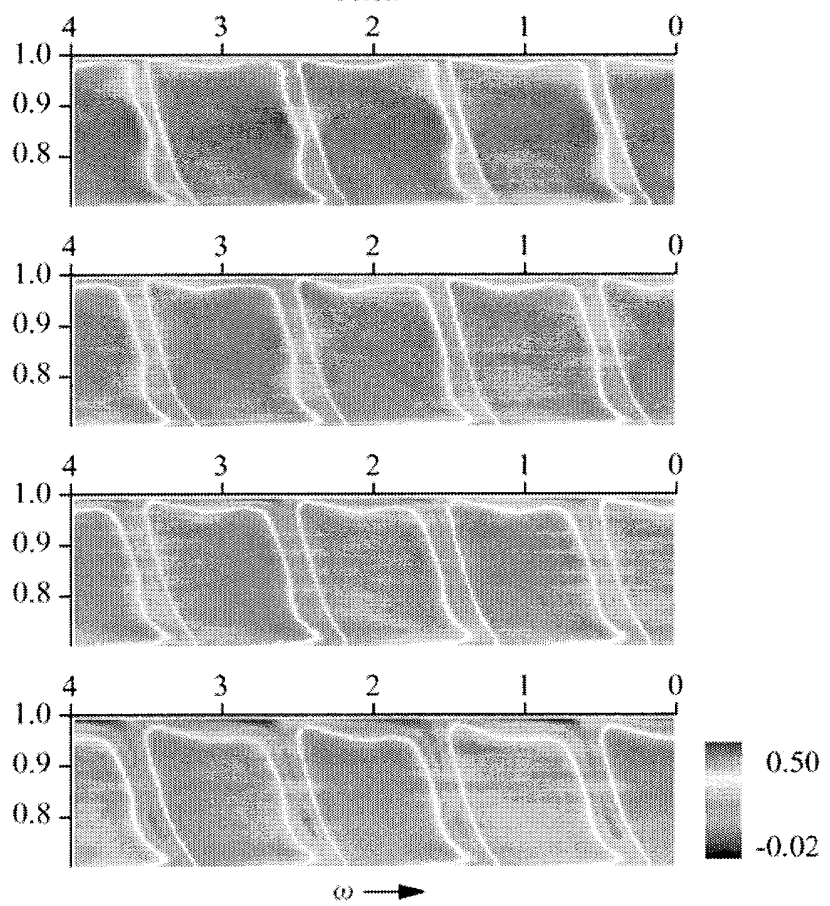

(b) $\tau=1 \%$

Fig. 4 Axial velocity distributions downstream of the rotor 
が小さいことを示している．また，動翼負圧面における速度 欠損域は， $\tau=3 \%$ 場合に比べ厚いことがわかる. $\phi=0.38$ から $\phi=0.36$ にかけて，ケーシング面近傍における速度欠損 域はスパン方向にわずかに拡大しているが， $\tau=3 \%$ の場合に 比べその領域は小さく, 依然として翼端漏れ渦によるブロッ ケージ効果は小さい，しかし，ウェーク領域は周方向に拡大 しており， $\tau=3 \%$ の場合に比べ厚くなっている。これは流量 の減少により翼負圧面境界層が発達し, ウェークの二次流れ が強くなったためであると考えられる. $\phi=0.34$ ではさらに この領域は拡大し, ウェーク領域が流れ場に大きな影響を及 ぼしていると言える。また，ケーシング面近傍ではわずかに 逆流を生じており， $\tau=3 \%$ の場合に比べ翼端漏れ流れの影響 が大きいことが分かる.

図 5 に動翼後縁 $8.0 \mathrm{~mm}$ 下流における流れの乱れ度分布 T.L. （動翼先端周速に相当した動圧で無次元化）を示す．戝の表 示方法は図 4 と同様である.

$\tau=3 \%$ において， $\phi=0.40$ の分布図を見ると，翼間のケー シング面近傍において分散值の高い領域が確認される。この 領域は図 4 の $\mathrm{Cz}$ の速度欠損域と対応しており，翼端漏れ渦 による流れの乱れであると考えられる. $\phi=0.38$ から $\phi=0.36$ にかけて，この高分散值領域はスパン方向に拡大しており， さらにウェーク領域においても高分散值領域が周方向に拡 大している。これは図 4 の $\mathrm{Cz}$ の速度欠損域の拡大とよく一 致している. $\phi=0.34$ に至ると，ケーシング面近傍での分散 值は急激に高くなる。これは先に述べた，翼端漏れ渦の渦崩 壊による影響であると考えられる．以上のことから， $\tau=3 \%$ の場合における流れ場は翼端漏れ渦が支配的であると言え る.

$\tau=1 \%$ において， $\phi=0.40$ の分布図を見ると， $\tau=3 \%$ の場 合に比ベケーシング面近傍における高分散值領域のスパン 方向への拡がりが小さいことが分かる。これは $\tau=1 \%$ 場合 の方が翼端漏れ渦が弱いことに起因しており，流れ場に及ぼ す影響は比較的小さいと考えられる。
ここで，ウェーク領域での乱れ度について，翼端すき閒が 及ぼす影響の違いを考察する。 $\phi=0.40,0.38$ において翼端 すき間による高分散值領域の差異はみられない. しかし， $=0.36$ より低流量になると， $\tau=1 \%$ の場合の方が $\tau=3 \%$ の場 合に比べウェーク領域における乱れ度が高く，その領域は周 方向へ広い。この違いは以下に述べるような過程を経て発生 すると考えられる。まず， $\phi=0.40,0.38$ では翼端すき間の 大小に関わらず，流量の減少が迎え角の増大による翼負荷の 増大をもたらし，翼負圧面境界層が発達する。 $\phi=0.36$ より 低流量になると， $\tau=3 \%$ の場合では翼端漏孔渦のスパイラル 型崩壊に伴う大きなブロッケーージ効果が生じ，その効果によ り主流が増速され，翼負圧面境界層の発達が抑制される結果， ウェーク領域の乱れ度の増加が抑制されると考えられる。一 方， $\tau=1 \%$ の場合では，翼端漏れ渦の崩壊は発生せず，この ような翼負圧面境界層の発達を抑制する要因はない。した がって, 翼負圧面境界層が発達する結果, 弱いはく離と再付 着が繰り返し発生し, 乱れ度の高い流れ場を作り出している と考えられる.

4-2 壁面静圧分布測定 眓 6, 図 7 にそれぞれケーシング壁 面に㧍ける静圧の平均值分布 $\mathrm{Pw}$ (動翼先端周速に相当した 動圧で無次元化)，およびその分散值分布Pdev を示している. 図中(a)，(b)は翼端すき間がそれぞれ $\tau=3 \% ， 1 \%$ の場合の測 定結果であり，上から流量係数 $\phi=0.40,0.38,0.36,0.34$ の 順で表示している。また横軸に Pitch 番号, 図の下部に動翼 回転方向を示している。

図 6 に执いて $\tau=3 \%$ の場合を見ると， $\phi=0.40$ で翼負圧面 の前縁付近から圧力の谷が翼間に伸びている.これは翼端漏 れ渦の低圧領域が捉えられたものである。これに相当する領 域が図 7 において高分散值領域として明確に現れている.流 量が減少し, 翼端漏れ渦がスパイラル型の崩壊を起こす $\phi$ $=0.36$ では，図 6 においてこの圧力の谷は不明瞭になり，そ れに伴いこの領域での圧力分散值が高くなる。これは，崩壊 した翼端漏れ渦が翼間で非定常的に摇動していることを示
T.L.

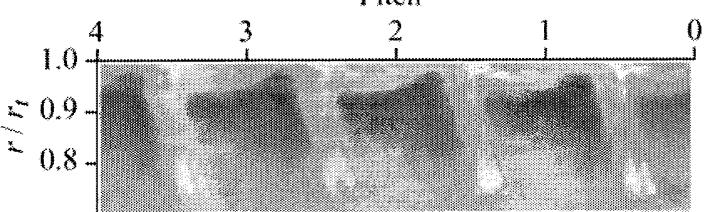

$\phi=0.38$

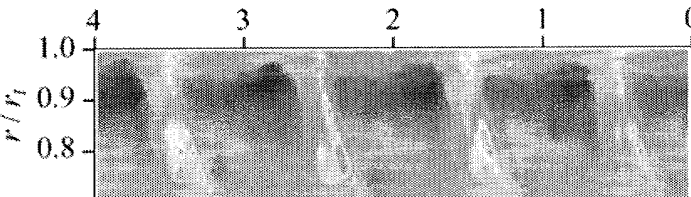

$\phi=0.36$

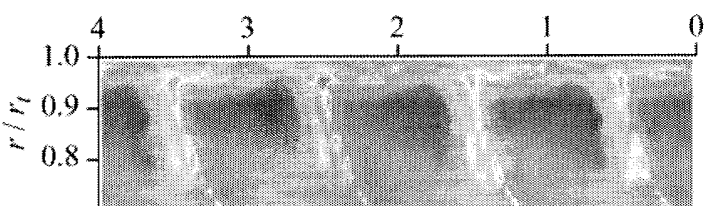

$\phi=0.34$

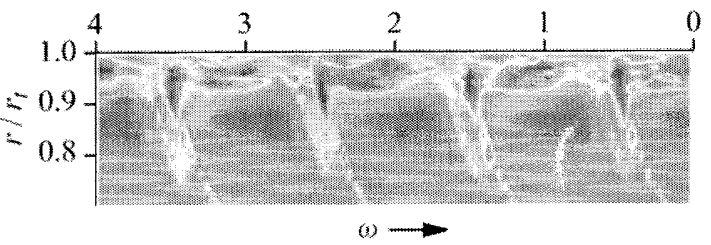

(a) $\tau=3 \%$
T.L.
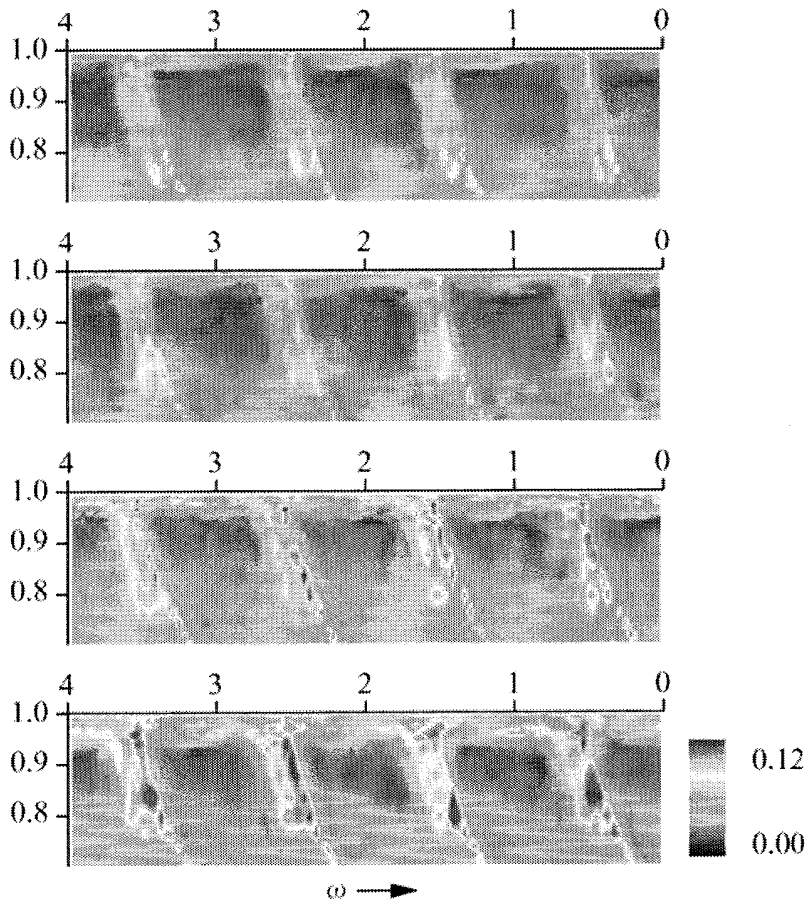

(b) $\tau=1 \%$

Fig. 5 Turbulence Intensity distributions downstream of the rotor 
している. $\phi=0.34$ では, 図 7 にお゙いて翼圧力面での分散值 が急激に高くなり，崩壊した翼端漏れ渦が隣接翼圧力面と強 く干渉している様子を捉えている.

一方， $\tau=1 \%$ 場合において図 6 の $\phi=0.40$ を見ると， $\tau$ $=3 \%$ の場合に見られた翼端漏れ渦による圧力の谷は小さく なっており，翼端漏れ渦が弱いことがわかる．また，そのと きの分散值分布図（図 7）から， $\tau=1 \%$ における翼端漏れ渦 の非定常性は小さいといえる. $\phi=0.38$ から $\phi=0.36$ にかけて, 図 6 では翼圧力面と負压面の圧力差が増加しているが，翼端 漏れ渦の挙動に変化は見られない。このとき図 7 を見ると, 翼負圧面の後縁付近に分散值の高い領域が見られる。これは 翼負荷の増加に伴い, 負圧面境界層の弱いはく離と再付着が 発生していることによるものであると考えられる. 失速点近 傍である $\phi=0.34$ において，図 6 では翼圧力面と負圧面の圧 力差はさらに増加し， $\tau=3 \%$ の場合に比べ翼負荷が大きいこ とがわかる。このとき，図７では翼負圧面の後縁付近でさら に分散值が高くなっておうり，翼負圧面での非定常性がさらに 高くなっている.また, 翼端漏れ渦に相当する高分散值領域 が確認できることから，渦崩壊は起きていないと言える.

以上の解析から，ケーシング壁面の圧力場からも， $\tau=3 \%$ の場合は翼端漏れ渦の崩壊が流れ場を支配しており， $\tau=1 \%$ の場合は翼負圧面境界層のはく離が流れ場を支配している と考えられる.

\section{5.結 言}

本研究では，翼端すき間が大きな場合と小さな場合の軸流 圧縮機について, 動翼列下流における内部流動測定とケーシ ング壁面における静圧測定とを実施し，内部流孔構造とその 非定常挙動に及ぼす翼端すき間の影響について調査をおこ なった.

その結果, 以下の知見が得られた。

翼端すき閒が大きな場合：

1）翼端すき間が大きいために翼端の漏れ流れが強く生じ これが翼端漏れ渦として強く巻き上がる.

PW
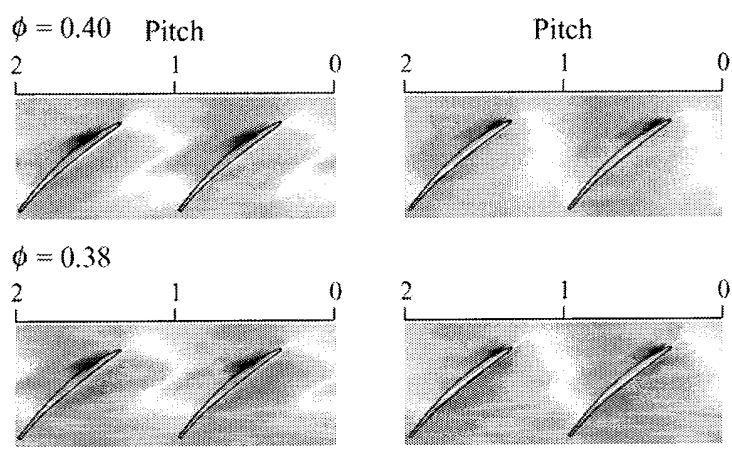

$\phi=0.36$
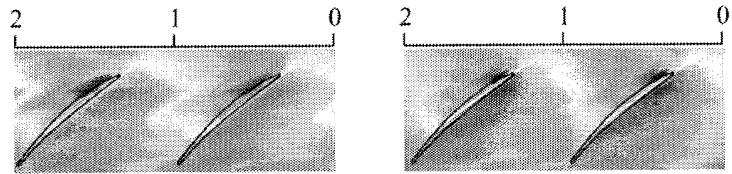

$\phi=0.34$

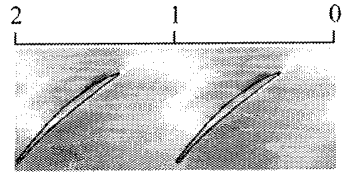

(1) $\longrightarrow$

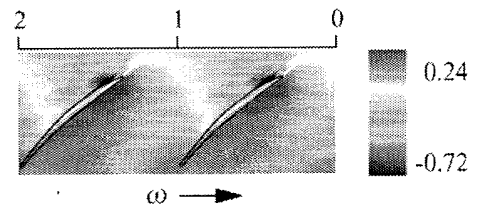

(a) $\tau=3 \%$

(b) $\tau=1 \%$

Fig. 6 Pressure distributions on the casing wall
2）失速点近傍においては，迎え角の増大に伴って翼負荷 が増大して翼端漏れ渦がさらに強くなり, 翼端漏れ渦 のスパイラル型渦崩壊が生じる。その結果，ケーシン グ面近傍で強い非定常性が現れる。

3）翼端漏れ渦の崩壊に起因した翼端部のブロッケージ効 果が主流部の增速を引き起こし，翼負压面の境界層の 発達が抑制される。

翼端すき間が小さな場合：

1）翼端漏れ渦の影響は顕著に現れない。

2）流量の減少に伴い迎え角が増大する結果，翼負圧面の 境界層が発達しウェークが厚くなる.

3）失速点近傍においては，翼負圧面の境界層が発達し非 常に不安定な状態となり，弱いはく離を生じる，その 結果，動翼のウェーク内に強い非定常性が現れる.

以上のことから，翼端すき間が大きな場合の失速初生は翼端 漏れ渦が支配的であり，翼端すき間が小さな場合の失速初生 は翼負圧面境界層のはく離が支配的であると考えられる。

\section{引用文献}

(1) Inoue, M., Kuroumaru, M., Yoshida, S., Minami, T., Yamada, K. and Furukawa, M., 2004, "Effect of Tip Clearance on Stall Evolution Process in a Low-Speed Axial Compressor Stage," ASME Paper, No.GT2004-53354.

(2) 太田黑竜佑，亀田拓郎，九郎丸元雄，古川雅人，“軸流 圧縮機動翼列における旋回不安定じょう乱の非定常挙 動”, 日本機械学会流体工学部門講演会講演概要集 (2005), No.05-32 pp.226

(3) 井上, ほか 5 名，1998，日本機械学会講演論文集， No. 98-15, pp. 211-212

（4）九郎丸元雄，ほか 4 名，1982，“周期的多点抽出法による 羽根車後方の三次元流れ場の計測 “, 日本機械学会論文 集, 48 巻 427 号, B 編, pp. 408-417

Pdev
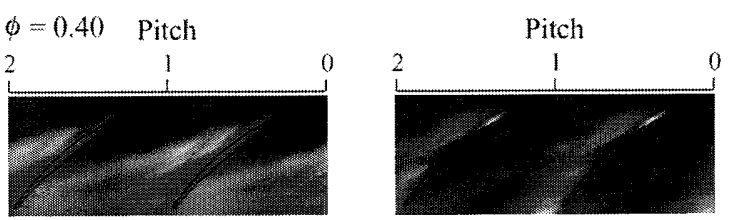

$\phi=0.38$
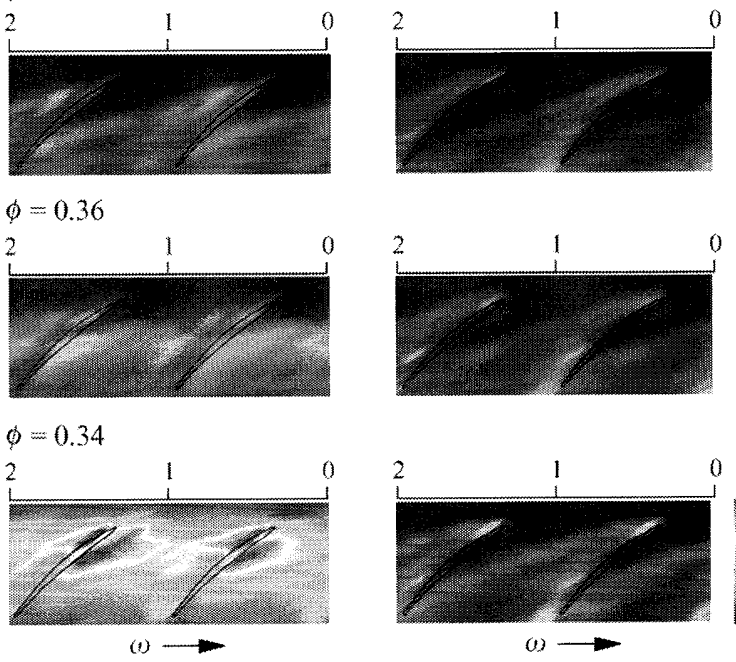

(a) $\tau=3 \%$

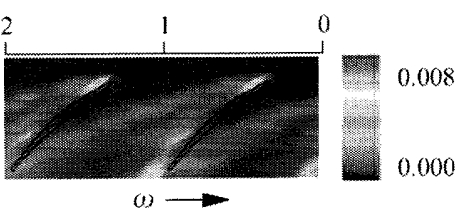

(b) $\tau=1 \%$

Fig. 7 Pressure fluctuation distributions on the casing wall 